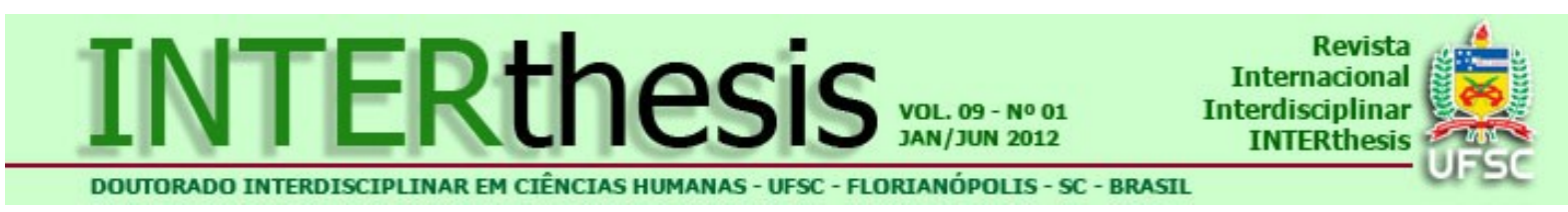

\title{
AUTODESCONSTRUÇÂO NARRATIVA NO CINEMA CONTEMPORÂNEO: A EMERGÊNCIA DE QUESTÕES ONTOLÓGICAS EM MCQUEEN E ESMIR FILHO ${ }^{1}$
}

\section{NARRATIVE SELF-DECONSTRUCTION IN CONTEMPORARY CINEMA: THE EMERGENCE OF ONTOLOGICAL ISSUES IN MCQUEEN AND ESMIR FILHO}

\begin{abstract}
AUTODECONSTRUCCIÓN NARRATIVA EN EL CINE CONTEMPORÁNEO: EL SURGIMIENTO DE CUESTIONES ONTOLÓGICAS EN MCQUEEN Y ESMIR FILHO
\end{abstract}

Alessandro $\mathrm{Zir}^{2}$

\begin{abstract}
RESUMO:
Este ensaio examina, a partir de dois exemplos (Hunger e Os famosos e os duendes da morte), o processo de emancipação, no cinema contemporâneo, de elementos icônicos, visuais e sonoros, com relação à sua função narrativa. Busca-se caracterizar esse processo como uma autodesconstrução da unidade conceitual dessas obras, a qual possibilita a emergência de questões de ordem ontológica, fundamentais à experiência estética para além das suas dimensões psicológicosociais. O ensaio se inicia com uma discussão de pressupostos teóricos de base, remontando a autores como Heidegger e Blanchot, para em seguida, durante a análise concreta dos casos estudados, fazer referência também a pesquisas mais recentes e especificamente relevantes para a área de cinema, como os estudos de Michel Chion sobre L'audio-vision.
\end{abstract}

Palavras-chave: Imagem. Som. Écriture. Desconstrução. Cinema.

\section{ABSTRACT:}

Relying on the analyses of two examples (Hunger and Os famosos e os duendes da morte), this essay examines the process of emancipation of iconic (visual and audio) elements in relation to their narrative function in contemporary cinema. This process is characterized as a deconstruction of the conceptual unity of these works, which enables the emergence of ontological issues that are fundamental to aesthetic experience beyond its psychological and social dimensions. The essay begins with a discussion of theoretical grounds going back to authors such as Heidegger and Blanchot. In what follows this discussion, during the concrete analysis of the

\footnotetext{
${ }^{1}$ Trabalho apresentado no I Congresso Intemacional Texto-Imagem (Universidade Federal de São Paulo), Guarulhos, outubro de 2010.

${ }^{2}$ Doutor pelo Interdisciplinary PhD Program da Dalhousie University (Halifax, Canada). Membro do GIFHC (Grupo Interdisciplinar em Filosofia e História das Ciências), do ILEA (Instituto LatinoAmericano de Estudos Avançados da UFRGS). Desenvolve pesquisa de pós-doutorado junto ao Programa de Pós-graduação Interdisciplinar em Ciências Humanas (PPGICH) da Universidade Federal de Santa Catarina (UFSC). E-mail: azir@dal.ca
}

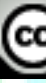


examined films, references are made to more recent researches specifically connected to the field of film studies, such as Michel Chion's L'audio-vision.

Keywords: Image. Sound. Écriture. Deconstruction. Cinema.

\section{RESUMEN:}

Este ensayo analiza, a partir de dos ejemplos (Hunger y Os famosos e os duendes da morte), el proceso de emancipación de elementos icónicos, visuales y sonoros con relación a su función narrativa en el cine contemporáneo. Se pretende caracterizar este proceso como una autodeconstrucción de la unidad conceptual de esas obras, lo que permite el surgimiento de cuestiones de orden ontológico, fundamentales a la experiencia estética más allá de sus dimensiones psicosociales. El ensayo comienza con un análisis de hipótesis teóricas de base, que se remontan a autores como Heidegger y Blanchot, para enseguida, durante el análisis específico de los casos estudiados, hacer también referéncia a otras investigaciones más recientes y relevantes para el ámbito del cine, como los estudios de Michel Chion sobre L'audio-vision.

Palabras clave: Imagen. Sonido. Écriture. Deconstrucción. Cine.

\section{BASES HISTÓRICO-CONCEITUAIS DA DISCUSSÃO PROPOSTA}

No segundo volume das suas aulas publicadas sobre Nietzsche, Heidegger nos fala do conceito como unidade remetida a si do sujeito de conhecimento (HEIDEGGER, 1961, p. 462-465). Os comentários de Heidegger são como breves anotações que o pensador faz para si mesmo. Em termos da história da filosofia, eles nos remetem à tradição kantiana.

De acordo com essa tradição, a possibilidade de dar sentido à experiência depende de um ato espontâneo do entendimento, da nossa faculdade de representação, que sintetiza a diversidade de impressões que nos são dadas na sensibilidade. O que serve de base para a síntese é a necessidade do "eu penso" acompanhar todas as minhas representações - de outra forma, algo seria representado em mim que eu não poderia pensar, quer dizer, a representação seria impossível, ou pelo menos não seria nada, em relação a mim. O "eu penso" que acompanha as representações é uma pura apercepção (não empírica). Qualquer pensamento determinado, significativo, pressupõe a possibilidade dessa pura apercepção (que nunca nos é inteiramente dada ela mesma) (Von der ursprünglichsynthetischen Einheit der Apperception, KANT, 2009, p. 147-50).

Mas, dentro dessa mesma tradição, qualquer pensamento determinado pressupõe também formas a priori da sensibilidade, quer dizer, o espaço e o tempo 
(e sobretudo o tempo, que é condição das percepções tanto externas quanto internas). E essa é uma condição que afeta também o "eu penso", na medida em que essa proposição pode ser ela mesma pensada. Há aqui um nódulo tenso da metafísica ocidental moderna, que vai ser explorado posteriormente por autores como Schelling, Kierkegaard e Heidegger, o qual diz respeito a como a nossa experiência do tempo possibilita, determina, mas também põe em cheque, suspende, desloca, a possibilidade de síntese cognitiva, a possibilidade de sentido, de constituição, pelo sujeito, de um discurso significativo a respeito da experiência que ele tem das coisas e de si mesmo (ROBERTS, 1988, p. 128). ${ }^{3}$

Esse nódulo é o ponto em que o sentido sempre pode exceder a si mesmo, e deixar de fazer sentido. Trata-se de um ponto que não se pode agarrar conceitualmente, tampouco expressar com clareza através de uma imagem ou intuição, e nem mesmo através do silêncio. Tal dificuldade atravessa a filosofia moderna e contemporânea. Ela explica, por exemplo, a crítica feita por Jacques Derrida a Michel Foucault, no célebre ensaio Cogito et le Histoire de la Folie (1967). Como aponta Derrida, aquilo que Foucault teria procurado resgatar, em seu projeto de uma arqueologia da loucura, como um outro da razão, não deixa de ser, paradoxalmente, a própria razão em seu excesso. Esse excesso é o que Foucault, malgrado suas intenções, não conseguiria dizer em Histoire de la folie à l'âge classique (1972) - e tal excesso não pode ser dito em nenhum outro livro. Só de forma indireta e metafórica ele se faz presente. E a metáfora aqui não é figura silenciosa que se pudesse opor ao discurso, mas o discurso ele mesmo em sua instabilidade intrínseca. Uma instabilidade que não pode ser e não pode ser senão figurada.

Nas palavras de outro leitor de Heidegger, Maurice Blanchot - aquele que é mais que um herdeiro dessa problemática, à medida que ele a repensa de forma

\footnotetext{
${ }^{3}$ Em Cinéma 1: L'Image-Mouvement, Gilles Deleuze se refere, nesse sentido, a uma correlação crucial entre as concepções de Heidegger e Bergson sobre o tempo: ambas implicam uma subversão das concepções tradicionais de subjetividade e representação (Deleuze, 1983, p. 20, n. 14). Bernard Stiegler é outro autor que caberia aqui referir, enquanto herdeiro vivo dessa tradição, na medida em que ele entende a emergência da consciência humana, desde a pré-história, em termos de uma "externalização" e de uma "temporalização", mediadas pela técnica: "as aporias que abrem a questão da antecipação são aquelas mesmas que constituem o paradoxo da exteriorização; um conter [retard] que é também um avanço, a estrutura resultante de um corte [après-coup] em que nunca somos capazes de dizer se é o córtex que torna possível o sílex ou o inverso. O interior deveria preceder o exterior à medida mesma que ele é constituído por esse último, que o precede, portanto" (Stiegler, 1994, p. 183-84).
}

R. Inter. Interdisc. INTERthesis, Florianópolis, v.9, n.1, p.349-361, Jan./Jul. 2012 
original no âmbito da experiência literária - o silêncio, que é o outro do sentido, é o "cochicho de uma dimensão sem mesura" [immensité chuchotante], "o derramamento cintilante do fora" [ruissellement du dehors] (BLANCHOT, 1955, p. $56,101)$. Ele emerge no âmago do próprio sujeito como uma espécie de neutro eloquente. É o estranhamento experimentado pelo narrador de Igitur de Mallarmé, quando a batida do próprio coração assusta como um outro de si mesmo: "J'entends la pulsation de mon propre coeur. Je n'aime pas ce bruit..." (BLANCHOT, 1955, p. 145; MALLARME, 2003, p. 41). Esse estranhamento, essa ausência, "não é puro", "não se opõe ao dia pelo repouso, o cessar das tarefas". Em suma, "o silêncio fala" [le silence est parole] (BLANCHOT, 1955, p. 150; cf. 205; BLANCHOT, 1959, p. 29799). ${ }^{4}$ Ele inaugura e permite também desconstruir aquilo que Heidegger denomina de história da metafísica ocidental. Nele pululam questões de ordem ontológica, que agora gostaríamos de explorar a partir da análise concreta de duas obras cinematográficas.

\section{HUNGER}

Hunger é um filme irlandês de 2008. O primeiro filme do seu diretor, Steve McQueen, que com ele ganhou o Câmera de Ouro, no festival de Cannes. Aparentemente um filme político, aquilo que seria o seu mote aparece escrito em letra branca miúda sobre um fundo negro, logo na abertura: a retirada, pelo governo britânico, do status político de todos os prisioneiros paramilitares (do exército republicano irlandês). Mas tal mote é mostrado de forma muito recatada e discreta, e o que se sobrepõe a ele em seguida, e ainda na abertura, é o som de um protesto ocorrendo nas ruas. Não se trata de um protesto articulado. Ele sequer é feito de vozes humanas, mas sim de objetos, como tampas de panelas, batendo violentamente contra o chão, de uma forma ritmada. A câmera então nos mostra o rosto de uma das jovens que está produzindo o barulho. A coloração marrom-escura

\footnotetext{
${ }^{4}$ Tal silêncio, imensidão murmurante e barulho do fora, emerge sobretudo a partir de atividades relacionadas àquilo que se denomina de "l'écriture", termo chave que, conforme sintetiza Jean-Luc Nancy, "designa para Blanchot - e para essa comunidade de pensamento que conecta, todos juntos, Bataille e Adorno, Barthes e a Derrida - o movimento de exposição a essa fuga do sentido que retira do 'sentido' o significar para lhe render o sentido mesmo dessa fuga [le movement d'exposition à cette fuite du sens qui retire au "sens" la signification pour lui donner le sens même de cette fuite]: um arrebatamento, uma abertura, uma exposição incansável [inlassable] e que, portanto, nem mesmo 'foge', que foge tanto da fuga quanto da presença" (NANCY, 2005, p. 130).
}

R. Inter. Interdisc. INTERthesis, Florianópolis, v.9, n.1, p.349-361, Jan./Jul. 2012 
da cena remete ao marrom da merda acumulada nas paredes - ao no-wash protest, o outro protesto, feito dentro da Her Magesty Prison Maze, pelos republicanos irlandeses presos, que é um dos focos recorrentes da narrativa. Silêncio e vê-se o título do filme: Hunger.

A abertura é coerente com tudo o que vai se seguir depois na tela. O que sustenta o filme do início ao fim não é um discurso ou contra-discurso político, e nem mesmo uma história. É essa tensão permanente entre uma sequência de sons intensos, ásperos e agressivos, cortados repentinamente pelo silêncio. No que seria a primeira cena do filme, por exemplo, vemos o policial tomando o seu café da manhã. O que se sobressai aqui são os ruídos amplificados - com diversos "índices de textura", como diria Michel Chion (2011, p. 99) - dos farelos de torrada caindo no guardanapo, seguidos dos ruídos da porta da rua da casa abrindo e fechando, das dobradiças do portão de metal, dos passos do homem contra o piso e o asfalto. Até que ele, do lado de fora, para e olha para o final da rua, e em silêncio mostra-se a fachada das casas sem nenhuma movimentação. Outros momentos de silêncio rodeados de ruído são as passagens do policial fumando na neve, encostado na parede externa da prisão. Os flocos de neve caem silenciosos e são visíveis apenas pelo contraste formado com a calça preta do uniforme. Mas dessa forma, cada um deles acaba como que sublinhado, num movimento de desaceleração daquilo que Chion chama de "micro-rythmes visuels" (2011, p. 18). A câmera vai se aproximando devagar e vemos feridas cicatrizadas no dorso da mão do policial. Essas feridas agora se expressam através dos sons da brasa do cigarro queimando, que são seguidos dos passos de um rato que aparece no chão, ao lado, correndo encostado à parede, na direção oposta do homem.

Outro ponto a ser considerado é que muitos dos sons ásperos e agressivos que se entrelaçam com o silêncio ao longo de todo o filme são amplificações de uma infinidade de ruídos "insignificantes": ranger de dobradiças, tilintar de chaves, passos, o riscar de uma caneta de encontro ao caderno de registro de entrada dos presos, o roçar de uma roupa na outra, o zumbir das asas de uma mosca, papel de alumínio sendo revirado e amassado no refeitório dos guardas, os dedos de um preso roçando na tela de metal retorcida da janela da cela, merda sendo espalhada nas paredes, mijo sendo vertido dos penicos no chão das celas até se espalhar pelos corredores, as folhas da bíblia sendo enroladas como cigarros, os bilhetinhos 
escritos em letras minúsculas sendo dobrados e escondidos, desdobrados e lidos etc. O filme amplifica todos esses ruídos aparentemente insignificantes e se dá no espaço dessa intensidade sonora insuspeita.

O que há aqui, em primeiro lugar, é uma desconstrução daquilo que Chion denomina de "voco-centrisme" e "verbo-centrisme" do cinema: a primazia estrutural da voz e da palavra significativa com relação a outros sons, não humanos (CHIOn, 2011, p. 9-11). É como se, daquilo que Chion denomina de "hors-champ passive", emergissem uma série de "sons-territoire" e elementos sonoros da locação (2011, p. 75-76), os quais, por sua vez, ganhariam proeminência com relação à narrativa. ${ }^{5}$ É de um "quase nada", entremeado frequentemente com o silêncio, que emerge a violência mais ensurdecedora, como quando os prisioneiros quebram os móveis das celas novas a que tinham sido transferidos. O acesso de fúria em questão assoma insuspeito, mas vigorosa e paulatinamente, como um crescendo, a partir do percutir leve e nervoso da ponta do pé de um dos presos contra o chão da cela, em cuja cama ele está sentado, sozinho. O filme de McQueen estaria assim à altura daquele desafio que, segundo Chion, raramente teria sido enfrentado no cinema: conceder aos ruídos, enquanto tais, "o estatuto de elementos cinematográficos integrais" [à part entière]; conceder aos ruídos, para além de uma função meramente ilustrativa, "a mesma capacidade expressiva concedida à luz, ao enquadramento, à interpretação dos atores" (2011. p. 126).

Não obstante à preponderância dos ruídos, Hunger é literalmente cortado ao meio, por um diálogo de cerca de 20 minutos, entre o personagem principal e um padre que vem visitá-lo na prisão. O diálogo tem uma inteligibilidade difícil, sendo rico em referências toponímicas e fatos do passado dos personagens que em nenhum momento são explicados. É como se a conversa não se passasse ali, mas em algum outro lugar geográfico fora da prisão, e em um tempo indeterminado (os personagens se chamam, respectivamente, de Wee-Boy e Dom). Trata-se de uma espécie de "idle banter", que lembra diálogos destes outros dois irlandeses, James Joyce e Samuel Beckett, em que palavras são postas em circulação de uma forma cômica e ao mesmo tempo angustiada, sem que nunca se consiga chegar ao objetivo da conversa. O objetivo, a que os dois interlocutores nunca chegam, e que

\footnotetext{
${ }^{5}$ Desenvolvimentos de ordem técnica, relacionados ao sistema de som Dolby multipistas, favorecem esse tipo de emergência, que Chion denomina de super-champ (2011, p. 75, 77, 123, 125, 127-128, 130-132).
}

R. Inter. Interdisc. INTERthesis, Florianópolis, v.9, n.1, p.349-361, Jan./Jul. 2012 
quando chegam perdem, é o estatuto, o sentido, o valor da resposta mais radical a ser dada pelos presos paramilitares à perda do seu status político: a greve de fome. Sabe-se de antemão que o governo não vai deixar-se mobilizar por tal estratégia. Os presos só se engajam nela porque, de certa forma, já estão mortos. Mas mortos de um tipo de morte que não ocorre, que é fora de lugar. Nem suicídio e nem homicídio, e muito menos morte natural. Ela não visa entrar na história e, se é feita em nome de uma liberdade, trata-se de uma espécie de liberdade total, que não pode ser negociada, inegociável.

O objetivo do diálogo, que é uma espécie de acerto em torno dessa morte, vai deslocando toda a conversa para fora do político, para fora do universo humanocomunitário de sentido, para fora daquilo que poderia ser um sentido comum. $E$ tal deslocamento, paradoxalmente, não implica um desprezo pela vida, ao contrário. No momento em que se decide a morrer, o personagem diz: "my life means everything to me, freedom means everything". É que vida e liberdade são acionadas aqui em um registro no limite do humano, de um devir animal, em que a morte do personagem, ao invés de se apagar, se desdobra na morte de um potro sacrificado pelas mãos de uma criança. Imagem em off, invisível, apenas referida, nunca mostrada, e de difícil explicação. Explicá-la seria tornar-se inumano, correndo o risco do humanismo mais ingênuo: pensar o diálogo não mais como um chitchat insensato, mas como a promessa niilista da felicidade como finalização da dor; quer dizer, como o silêncio mais absoluto, que no filme, entretanto, está sempre entremeado de ruído.

De fato, assim como o silêncio de todas as outras passagens era apenas aparente, o que ficava patente na amplificação da sua apenas aparente insignificância, a morte aqui proposta, que de certa forma nunca acontece, e não pode ser entendida literalmente, é o oposto de uma passividade negativa rumo ao inexpressivo. Aquilo que a greve de fome gera é uma decomposição em vida do corpo, que grita, ora surda, nas chagas do personagem (semelhantes às feridas do policial), ora barulhenta como uma revoada de pássaros amplificada e confundida aos seus espasmos de estertor. Quanto mais o personagem emagrece, não é a leveza que ele encontra. Pelo contrário, enquanto ele fica cada vez mais fraco, as 
coisas ao redor ganham o peso de toda a sua densidade. ${ }^{6}$ Comparecem elementos de fora da prisão, tudo aquilo que não podia ser visto, e que se deixa agora entrever em uma dimensão como que anterior à visão propriamente dita: o filho do preso, que é também o potro que ele teve de sacrificar, afogando, com as próprias mãos, quando criança, e que não deixa, portanto, o filho, de ser ele mesmo (o pai, o preso), mais novo, um cavalo. O barulho ínfimo da vibração de uma lâmpada incandescente, que cresce e se sobrepõe à voz humana de um colega que o visita na cela. Ouve-se também o som repetido, intenso, repetitivo, eminentemente econômico, de uma gaita de fole (a música só aparece duas vezes ao longo de todo o filme, e depois no encerramento, com um piano), que produz um efeito, como diria Chion, "anenpathique": quer dizer, um efeito que, ao invés de convidar a uma participação emocional na trama, desvela o seu caráter mecânico, robótico - de autômato, quer dizer, de algo que ocorre em um nível que é avesso à consciência (p. 11-12).

O preso é um corredor de cross-country e a morte é esta espécie de maratona sem fim. $O$ que parece ser o fim, estas árvores que se mostram (e se escondem) no crepúsculo, já tinha sido mostrado antes: servia também de pano de fundo às palavras de nenhuma outra pessoa senão a própria Margareth Thatcher, anunciando o não reconhecimento do status político dos presos. O filme, sem dúvida, questiona o direito original dessa voz, mas sem com isso propor nenhum tipo de contradiscurso. Mais do que isso, ele mostra o ponto chave em que 0 contradiscurso inevitavelmente se enreda com o discurso oficial. Armadilha para a qual não há saída, mas que pode ser de certa forma suspensa, quer dizer, distendida infinitamente, de forma que se faça emergir a riqueza insuspeita e terrivelmente loquaz do silêncio que essa voz aparentemente sufoca.

\section{OS FAMOSOS E OS DUENDES DA MORTE}

De uma forma mais explícita que o filme anterior, Os Famosos e os Duendes da Morte (2010), dirigido pelo paulistano Esmir Filho, e filmado no Rio Grande do

\footnotetext{
${ }^{6}$ Em certo sentido, esse processo poderia ser caracterizado da maneira como Chion caracteriza o Homem Invisível (1933) de James Whale: para que o personagem seja invisível não se pressupõe "que ele seja feito de um corpo sutil... tudo nos mostra que lá está não um super-herói que voa, mas um corpo que sofre, um corpo que se faz presente em sua própria falta [corps em creux], e cujo caráter orgânico é sublinhado ao invés de ser abstraído [subtilisé]" (CHION, 2011, p. 108).
}

R. Inter. Interdisc. INTERthesis, Florianópolis, v.9, n.1, p.349-361, Jan./Jul. 2012 
Sul, se dá no espaço do "entre", entre imagem e texto/conceito, sendo uma espécie de diálogo cinematográfico com o livro homônimo de Ismael Caneppele (2010), o qual, por sua vez, já faz referências a filmes digitais, cujos links estão inseridos em suas páginas, tendo sido disponibilizados na internet. Esmir Filho recupera e se apropria não apenas do texto, mas dessas imagens (digitais) que fazem parte do livro de Caneppele, e que ele insere e reconfigura na película analógica do cinema. Mas o motivo pelo qual se pode considerar esse filme como paradigmático para a análise aqui proposta não é esta presença mais imediata, aparentemente mais visível, evidente, de um diálogo efetivo entre texto e imagem, propiciado, quem sabe de forma única, pela disponibilidade atual de um meio como a internet. Antes pelo contrário, Os Famosos e os Duendes da Morte é um filme que toca em questões que extrapolam uma mera representação daquilo que a crítica soube rotular como o universo da "adolescência blogueira" ou "geração youtube" (BEZERRA, 2010, p. 25). Como no caso de Hunger, o filme de Esmir Filho é exemplar por aquilo que, no contraponto entre texto e imagem, desfaz o texto e a imagem, torna o texto imagem e a imagem texto, riscando-se e desaparecendo nesse espaço sussurrante, intensamente barulhento, que se faz entre eles.

O primeiro contraste se dá, logo no início, entre a instabilidade das imagens digitais e o movimento extremamente suave e lento da filmagem "em película" que a sucede: esta aproximação paulatina de uma cabeça que aparece de costas, seguida do acompanhamento do girar de uma lâmpada de cabeceira (a câmera sobe em um ângulo paralelo, que mostra as paredes de madeira do quarto e do teto, conforme elas vão sendo iluminadas). Quando o movimento para, o clique do ascender e do apagar dessa lâmpada de cabeceira tem a intensidade de uma pulsação interior. E é também um clique visual: o contraste entre escuridão e luz, que permite ver as estrelas decalcadas no teto, a mãe dormindo sozinha no quarto ao lado (e mais tarde, alguém indesejável que retorna, parado diante da janela, no quarto do andar superior de uma casa ao longe; o farol de um carro que acende e apaga na estrada, como a emoção comum, compartilhada entre o motorista e o passageiro que atravessam, passam uma ponte, buscam uma saída da cidade). Desde a sua abertura, a história que o filme de Esmir Filho nos conta é esse desdobrar de coisas acontecendo em um espaço intermediário, difícil de localizar - o contraste entre 
isso e aquilo, nem isso nem aquilo, que se produz pela tensão não resolvida daquilo que se diferencia.

Mais do que os objetos focalizados, é a própria textura da imagem que se desdobra em sua materialidade, num estilo que lembra o Gus Van Sant de Paranoid Park (2007). ${ }^{7}$ Além das diferenças de granulação entre o digital e o analógico, entre a câmera e aquilo que é filmado interpõe-se inúmeros ruídos como, por exemplo, umidade, fumaça de cigarro e partículas de poeira que, à medida que refletem a luz, geram um tipo de bokeh hipnótico que distrai a atenção do que se poderia em princípio isolar como um conteúdo semântico da imagem. Nas muitas passagens escuras, há um forte contraste entre luz e sombra, e o que se vê dos personagens é um reflexo intenso em um recorte parcial da face, que às vezes não passa do seu contorno. O foco é frequentemente dividido, ele se concentra no universo de um dos personagens, e o restante se desfoca como uma moldura, quer dizer, o fora se intensifica e cola à sua superfície, tornando-se íntimo. Quando há dois personagens em cena, acontece de um se iluminar e o outro sumir na sombra, como na cena em que a mãe surge no quarto para chamar o filho para o almoço.

A passagem entre o digital e o "analógico", em certos casos, se vale explicitamente desses espaços opacos e íntimos de textura intensificada: o vidro embaciado da porta do boxe do banheiro, o espelho também embaciado que o menino limpa com a mão. Essa passagem não é uma simples troca de equipamento que permitiria um acesso diferenciado a uma mesma realidade, ela é a entrada em uma outra dimensão, que é a do hálito soprado diretamente na lente da câmera, ou a de uma pele craquelê, filmada de perto pela webcam como uma paisagem, um deserto de dunas coloridas ou uma pintura - o brilho furta-cor do celofane (que de encontro ao rosto, é também aquilo que sufoca, faz parar a respiração). Dessa dimensão emergem os dedos sujos de terra que se aproximam de nós como o barulho do vento no microfone da câmera, e toda uma riqueza de ruídos: grilos e

\footnotetext{
${ }^{7}$ Ao contrário do que foi observado por alguns críticos (Bezerra, 2010, p. 26), esse é o ponto real de contato dos dois cineastas (Gus Van Sant e Esmir Filho), para além da identidade imediatamente visível de certos tópicos comuns, como o de um objeto (bicicleta) que circula o personagem adolescente. Haveria, além disso, outras influências a destacar, que não precisam ser diretas. Os planos mais longos, como o inicial, em que a câmera se aproxima da cabeça do menino e depois acompanha o movimento da lâmpada de cabeceira (ou um outro em que os personagens vão sendo desdobrados em reflexos de espelhos que a câmera recolhe): eles remetem a uma tradição de cineastas como Andrei Tarkovsky (que junto com Bela Tarr, influenciaram previamente Gus Van Sant, e possivelmente Esmir Filho, mesmo que por caminhos indiretos).
}

R. Inter. Interdisc. INTERthesis, Florianópolis, v.9, n.1, p.349-361, Jan./Jul. 2012 
outros insetos noturnos, quero-queros e rãs, cães latindo, sinos dobrando, e também o riscar de um lápis que cochicha em meio ao silêncio de uma prova, as afinações e as microfonias que fazem parte das músicas da trilha.

Trata-se de uma passagem para "o mais foda", para "o depois dali, oh! Não tem mais nada", no dizer de Diego, personagem de Samuel Reginato (e também de "um troço ruim", que é ao mesmo tempo uma angústia e uma vontade de rir incontrolável). Mas é que ao invés de levar a um outro lugar, a passagem desintegra o lugar onde se está e o revela como um outro: é a cena em que um carrossel e as copas das árvores giram, degringolam em uma engrenagem contrária, e é difícil saber o que está por cima ou embaixo, as posições se invertem. Além de vozes irreconhecíveis, que são possivelmente da festa junina, ou ainda de um outro tempo, há nessa cena uma vibração surda e profunda, que é como o passar de um trem ou de um avião, mas na verdade é o correr do rio debaixo da ponte. Esse rio que quando dois jovens se atiram, se atiram no seu reflexo, e é como se mergulhassem no céu, assim como o diálogo prévio entre eles, em cima da ponte, já era feito por um futuro borbulhar saindo do fundo do rio e emergindo até a superfície. A passagem é, sobretudo, a cena do blackout, o momento em que o digital, que sinalizava sempre o passado, é absorvido pelo presente, absorve o presente e o transfigura, mostrando o encontro atual de três personagens que só poderia ter ocorrido num momento passado, antes de um deles morrer, mas no passado nunca ocorreu (como momento) e acontece agora (curto-circuitando todos os momentos). ${ }^{8}$ A passagem é por fim esse atravessar a ponte, que não é meramente pular dela (e mesmo quando se pula, talvez apenas se atravesse), mas ser desfocado, "desaparecer" em textura, em um borrão verde-amarelado cercado de preto.

\footnotetext{
${ }^{8}$ Entra-se em contato, aqui, com aquilo que Deleuze denomina de um "passé pur": "um passado" que não é apenas aquilo que o presente foi ou teria sido, mas aquilo que é o fundamento mesmo do presente, aquilo com relação a que o presente passa, o fundamento do presente, o céu sobre o qual o sol se move (Deleuze, 1968: 109). Tempo e memória são acionados numa dimensão que é antes ontológica do que psicológica, como se poderia dizer nessa tradição bergsoniana, em que o passado tem uma primazia com relação ao presente (DELEUZE, 1966, p. 51).
}

R. Inter. Interdisc. INTERthesis, Florianópolis, v.9, n.1, p.349-361, Jan./Jul. 2012 


\section{REFERÊNCIAS}

BEZERRA, J. Adolescência Blogueira. Revista de Cinema, São Paulo, ano X, n. 98, p. 25-27, mar./abr. 2010.

BLANCHOT, M. Le livre à venir. Paris: Gallimard, 1959.

BLANCHOT, M. L’espace littéraire. Paris: Gallimard, 1955.

CANEPPELE, I. Os famosos e os duendes da morte. São Paulo: Iluminuras, 2010.

CHION, M. L'audio-vision: son et image au cinema. Paris: Armand Colin, 2011.

DELEUZE, G. Cinéma 1: L'Image Mouvement. Paris: Les Éditions de Minuit, 1983.

DELEUZE, G. Différence et Répétition. Paris: Presses Universitaires de France, 1968.

DELEUZE, G. Le Bergsonisme. Paris: Presses Universitaires de France, 1966.

DERRIDA, J. L'écriture et la différence. Paris: Éditions du Seuil, 1967.

FILHO, E. Os Famosos e os Duendes da Morte. 2010.

FOUCAULT, M. Histoire de la folie à l'âge classique. Saint-Amand: Gallimard, 1972.

HEIDEGGER, M. Nietzsche. Pfullingen: Günther Neske, 1961.

KANT, I. Kritik der reinen Vernunft. Köln: Anaconda, 2009.

MALLARMÉ, S. Igitur. Divagations. Un coup de dés. Paris: Gallimard, 2003.

MCQUEEN, S. Hunger. 2008.

R. Inter. Interdisc. INTERthesis, Florianópolis, v.9, n.1, p.349-361, Jan./Jul. 2012 
NANCY, J.-L. La Déclosion: (Déconstruction du christianisme, 1). Paris: Galilée, 2005.

ROBERTS, J. German Philosophy. Atlantic Highlands: Humanities Press International, 1988.

STIEGLER, B. La technique et le temps 1: La Faute d'Épiméthée. Paris: Galilée, 1994.

VAN SANT, G. Paranoid Park. 2007.

Artigo:

Recebido em: 30/04/2012

Aceito em: 05/07/2012 